\title{
Teaching and Learning in the Time of COVID: The Student Perspective
}

\author{
Barbara Means and Julie Neisler \\ Digital Promise
}

\begin{abstract}
This article describes findings from the Survey of Student Perceptions of Remote Teaching and Learning, which was administered to a random national sample of 1,008 U.S. undergraduates taking for-credit college courses that began with in-person classes and shifted to remote instruction in spring 2020. Course satisfaction levels were much lower after courses moved online, and students recounted an array of barriers to their continued learning. More than 1 in 6 students experienced frequent internet connectivity issues and/or hardware and software problems severe enough to interfere with their ability to continue learning in their courses. Students from all backgrounds struggled to stay motivated and missed getting immediate instructor feedback and collaborating with their fellow students. Students of color and students from lower-income households experienced more challenges than did non-Hispanic White students and students from higher-income households. However, even with the challenges of an unplanned shift to remote learning, a majority of students were at least somewhat satisfied with their learning in the course after COVID, and satisfaction was higher for those courses using more of the practices recommended for effective online instruction.
\end{abstract}

Keywords: teaching and learning, online learning, COVID-19, students

Means, B., \& Neisler, J. (2021). Teaching and learning in the time of COVID: The student perspective. Online Learning, 25(1), 8-27. https://doi.org/10.24059/olj.v25i1.2496

\section{Teaching and Learning in the Time of COVID: The Student Perspective}

When the COVID-19 pandemic hit colleges in spring 2020, massive numbers of undergraduates and instructors who had not intended to be part of an online course were forced to continue teaching and learning at a distance. These were not individuals who sought online courses because of their convenience and scheduling flexibility nor instructors seeking to expand their skills repertoire. For the first time, the general population of college students was engaged in taking courses taught wholly online.

This dramatic shift immediately raised equity concerns. Despite the proliferation of broadband internet connections and computing devices, they are still lacking in many households, especially low-income households (Anderson \& Kumar, 2019). Educators questioned the fairness 
of holding students accountable for coursework deadlines and test performance when some students could not access essential course materials (Asch, 2020). Moreover, there is some evidence that students earn lower grades in courses taken online than in those with face-to-face meetings, and the difference is larger for students with lower levels of academic preparation (Bettinger \& Loeb, 2017; Xu \& Jaggars, 2011, 2013).

Prior research on student perceptions of online courses compared to courses taught through face-to-face instruction has found that the online courses are viewed as more flexible and compatible with other life activities such as work (Schwartzman, 2007) but as less effective for learning (Horspool \& Yang, 2010; Platt, Raile, \& Yu, 2014). Online courses are also viewed as offering fewer opportunities for interaction with other learners and the instructor (Bali \& Liu, 2018; Horspool \& Yang, 2010; Platt, Raile, \& Yu, 2014). The online courses students described in these studies, however, were from an earlier era of online instruction, and may not have featured newer technology applications supporting practices that research indicates foster learning at deeper levels. These include learner choice, interactivity, adaptivity, differentiated feedback, and linked representations (National Academies of Sciences, Engineering, and Medicine, 2017) as well as mechanisms for social interaction (Jaggars \& Xu, 2016), scaffolds for student reasoning and selfregulation (Dabbagh et al., 2019), and instructor use of learning system data to refine instructional activities (Fishman \& Dede, 2016). On the other hand, the online courses that were the focus of these studies were offered under normal circumstances, taken by students who chose to enroll in them, and taught by instructors who were likewise volunteers. Under these conditions, one might expect students to be more positive about the advantages of online instruction and less critical of its drawbacks. In addition, most of these studies focused on online and face-to-face versions of a single course taught at a single institution. Thus, data on student perceptions of online courses more broadly has been largely absent from the literature.

The experiences of students completing their courses online during the COVID-19 pandemic can inform us of course experiences and practices from a much broader set of courses that students find more and less satisfactory. The huge variation in instructional practices used in these remote courses can be mined for insights as to the practices that make online instruction more and less satisfactory to students. These student experiences also provide data on the prevalence and distribution of challenges students faced in pursuing their coursework remotely, particularly as those challenges relate to issues of equity. Colleges facing continued requirements for remote instruction can look to these findings to understand the needs of their undergraduate students and what they can do to provide courses their students find more satisfying.

A number of researchers have offered conceptual models for effective online learning experiences. The widely influential Community of Inquiry model developed at Athabasca University (Garrison, 2009), for example, draws attention to three dimensions of the online learning experience: The teaching dimension is the content and climate developed by the instructor; the social dimension involves developing interpersonal relationships and communicating in an environment of mutual trust; and the cognitive dimension involves constructing and confirming meaning around course content through dialogue and reflection. Bernard and colleagues (Bernard et al., 2009) used a similar three-part framework in their metaanalysis of studies comparing outcomes for different instructional modalities (fully face-to-face, blended, and fully online). For each study in their meta-analysis, they identified the instructional condition in which students had more interaction with course content (cognitive), more interaction with the instructor (teaching), and more interaction with their fellow students (social). This meta- 
analysis found that instructional conditions with a higher level of any of these types of interactivity produced better course outcomes. Jaggars and Xu (2016) also found evidence that the amount of student-instructor and student-student interaction in an online course predicts student course grades.

Research that does not involve online learning similarly points to the importance of peerto-peer and student-to-instructor interactions. Peer interactions and strong interpersonal relationships can increase students' sense of belonging (Ramsey et al., 2013; Smith et al., 2013), and students' sense of belonging is associated with student retention and persistence in their studies (National Academies of Sciences, Engineering, and Medicine, 2019; Smith et al., 2013; Strayhorn, 2012; Walton \& Cohen, 2011). Opportunities to collaborate with fellow students in peer instruction and in project-based learning have been found to enhance learning for all students but appear to have a particularly positive impact for students from minoritized groups (Freeman et al., 2014; Lichtenstein et al., 2014). In a related vein, studies of persistence in college programs suggest that some students perceive their instructors as unavailable or intimidating, leading to a low level of interaction with faculty, an experience associated with leaving a field of study (Daempfle, 2004). Perceptions of instructor responsiveness also appear to be important. Fouad et al. (2010) found that math and science teachers who were quick to help students who needed assistance had students with greater interest in pursuing careers in those fields. Another line of research suggests that instructors can contribute to students' sense of belonging and content mastery by increasing the amount of structure in a course and the transparency of their expectations for course assignments (Winkelmes, 2013). This practice appears to be especially helpful for students from minoritized race/ethnicity groups (Eddy \& Hogan, 2013; Winkelmes et al., 2016).

We developed the Survey of Student Perceptions of Remote Teaching and Learning and administered it to a national probability-based sample of undergraduates in spring 2020 to capture both course experiences and the difficulties students faced in trying to complete their courses during the COVID-19 pandemic. ${ }^{1}$ The resulting data set is distinctive not only because of the historic disruption ongoing when it was administered but also because of the construction of the student sample. Prior national surveys of college students learning online (e.g., Survey of Online Student Engagement; Time for Class) have not supported statistical inference because of very low response rates (typically $<10 \%$ ) and lack of a national probabilitybased sample. By using the college student segment of the Ipsos survey panel of 65,000 respondents, the present study rapidly obtained a quality postsecondary student survey sample permitting statistical inference. The sample represented the full diversity of the U.S. undergraduate population, including students in two-year as well as four-year postsecondary programs and parttime as well as full-time students.

Moreover, the sample of students and the courses they described in this research differ from prior studies of online and distance learning in that neither the students nor the instructors had expected these courses to be taught online. Hence, there was no self-selection bias in who was teaching and learning online.

\footnotetext{
${ }^{1}$ The original survey report is freely available at https://www.everylearnereverywhere.org/resources/suddenlyonline-national-undergraduate-survey/. This article presents some of the key insights from the larger report in addition to findings from a new set of original analyses conducted to build on those insights.
} 
The survey was designed to address three research questions:

- What challenges did students experience in learning remotely and how did challenges differ for low-income and minoritized race/ethnicity groups?

- What instructional practices did students experience and which instructional practices were associated with more positive student perceptions?

- Does the relationship between online instructional practices and student course satisfaction vary for different kinds of students?

\section{Methods}

\section{Instrument}

Digital Promise developed the Survey of Student Perceptions of Remote Teaching and Learning with support from Langer Research Associates to capture the experiences of undergraduates taking courses that transitioned to online instruction in response to the COVID-19 pandemic. The survey explores the nature of college courses as they were taught during the COVID-19 outbreak, the pervasiveness of various challenges undergraduates faced after the transition to remote instruction, and course features and instructional practices associated with higher levels of student satisfaction.

The survey included items on students' course experience with respect to a set of instructional practices that prior research suggests are associated with important student outcomes including course grades, college retention, and persistence in a field of study (National Academies of Sciences, Engineering, and Medicine, 2019). There is also research evidence (Freeman et al., 2014; Strayhorn, 2012; Winkelmes et al., 2016) that some of these course experiences, such as sense of belonging and clarity around course expectations, are especially consequential for minoritized groups (students from low-income backgrounds, students with disabilities, and women in most STEM fields, as well as those from minoritized race/ethnicity groups).

For purposes of keeping the student survey brief and easy to interpret, survey items corresponding to students' experience of these instructional practices were written in simple, everyday language. For example, transparency around course expectations was operationalized as "understanding what was expected of you in the course." Two aspects of instructor responsiveness were probed: "the instructor sending personal messages" and "the availability of help with the course content." Sense of belonging in the course was characterized as "your feeling included as a member of the class." The extent to which the course content was made interesting was expressed as "keeping you interested in the course content." Opportunities for collaborative learning and forming connections with peers were operationalized as "work on group projects" and "meeting in breakout groups during a live class."

\section{Sample}

The Survey of Student Perceptions of Remote Teaching and Learning was administered to a random national sample of U.S. undergraduates, age 18 and older, who were taking college courses for credit that included in-person class sessions when the COVID-19 pandemic hit and had to finish the course by learning at a distance. Ipsos Public Affairs conducted sampling and data collection via its online, probability-based KnowledgePanel ${ }^{\circledR}$, which administers internetbased surveys to randomly recruited participants in U.S. households. After answering screening 
questions designed to ascertain eligibility for the survey, respondents were asked to think about one particular course as they responded to the remaining survey questions. To increase the likelihood of uncovering challenges of remote instruction, the survey asked respondents to answer the survey questions for a STEM course if they were taking one. Courses in STEM subjects typically result in larger equity gaps in course outcomes (Blatt et al., 2020) as measured by course grades. Students who were taking more than one STEM course were asked to respond for the one they thought was most important for their future goals. Similarly, students who were not taking any STEM courses were asked to respond for the non-STEM course they considered most important for their future goals.

Field work was conducted between May 13 and June 1, 2020. Starting May 15, email reminders were sent to nonresponders every two days; those who did not respond by May 29 also received a reminder by telephone, and incentives (panel "points" that can be redeemed for prizes in future sweepstakes) were increased, first on May 27 and then again on May 29.

Of the 1,709 panelists initially responding, 1,014 were qualified undergraduates taking forcredit college courses that started with in-person classes and later went fully online in spring 2020. The median completion time for the survey was 10 minutes. Quality control flagged respondents who completed the survey in less than one-third of the median time, removing six cases, for a final sample size of 1,008 . The sample included 717 students attending four-year colleges, 271 students attending two-year colleges, and 20 students attending other types of postsecondary degree programs.

Students self-identified in terms of race/ethnicity when they joined the Ipsos survey panel. For survey data analysis, response codes to race and ethnicity items were used to form four groups: Black non-Hispanic, Hispanic, White non-Hispanic, and Multiracial or Other non-Hispanic. Analyses compared the experiences of non-Hispanic White students to those of Hispanic and Black students to better understand the disparate impacts of the transition to remote instruction. (There were too few students in other race/ethnicity categories to support reliable statistical estimates.)

\section{Analysis}

Data were weighted via iterative proportional fitting to the following benchmark distributions of adult undergraduate students with less than a bachelor's degree from the 2018 American Community Survey:

- Gender (male, female) by age (18-20, 21-22, 23-29, 30+)

- Race/ethnicity (White, Black, Other, Hispanic, 2+ races)

- Census region (Northeast, Midwest, South, West)

- Education (high school, some college, associate's degree)

- Household income (less than \$25,000, \$25,000-\$49,999, \$50,000-\$74,999, \$75,000$\$ 99,999, \$ 100,000-\$ 149,999, \$ 150,000+)$

- Language proficiency (English-proficient Hispanic, bilingual, or Spanish-proficient Hispanic, non-Hispanic)

- Hispanic nativity (U.S.-born, not-U.S.-born, non-Hispanic)

- School type (public, private) 
Weights were trimmed at $0.23 \%$ and $99.77 \%$ and then rescaled to match the sample size of all respondents. The final weights for qualified respondents were extracted from the above weights and rescaled to sum to the sample size of qualified respondents. The average design effect for the final weight is 1.35 , for a margin of error of 3.6 percentage points for the full sample. Error margins are larger for subgroups.

Weighted proportions of responses were used to assess statistical significance via Chisquare tests, correlations, and univariate and multivariate linear regressions where $p<0.05$ was used as the significance criterion. Data exploration and statistical analysis was completed in $\mathrm{R}$ Studio version 1.3.959.

\section{Limitations}

Several limitations of this research should be acknowledged. Students were asked to answer the survey questions for a STEM course if they were taking one. While this was done to increase the likelihood of uncovering challenges of remote instruction, it may have limited the study's generalizability to all undergraduate courses. Additionally, the survey was administered online and although it was designed to work on mobile phones, college students experiencing the most extreme issues with internet connectivity and device capabilities may have been less likely to be captured in the response pool. (Efforts to minimize any possible such limitation were completed through weighting on factors, including census region and household income, that are associated with access to internet and devices.) Finally, the generalizability of these findings may be limited by the fact that the survey was conducted during the early months of the COVID-19 pandemic; both students and faculty have gained additional experience with online instruction since that time.

\section{Results}

\section{Student Demographics}

Fifty-three percent of the weighted sample identified as female. Fifty-two percent identified as White, non-Hispanic, with 23\% identifying as Hispanic, 14\% identifying as Black, non-Hispanic, and $11 \%$ identifying as multiracial or other non-Hispanic. A total of $29 \%$ of students reported being in a household with less than $\$ 50,000$ annually, with another $29 \%$ reporting an annual income between $\$ 50,000$ and $\$ 100,000$, and the remaining $42 \%$ from households earning more than $\$ 100,000$ per year. Eleven percent of the sample reported being responsible for childcare following the transition to remote learning. Nearly half $(46 \%)$ of the sample reported being employed during their remote instruction, with 25\% working part-time (20 hours or less per week), and $21 \%$ working more than 20 hours per week. Over two-thirds (78\%) of the sample were aged between 18 and 25 years old.

\section{Nature of the Courses}

Subject Area. The subject matter in the focal courses that respondents chose to describe varied widely. Reflecting the fact that survey respondents were asked to describe a STEM course if they were taking one, $63 \%$ of students responded for a STEM course. The most common subjects for the courses that students described were biology (11\%), mathematics (10\%), computer science or technology $(8 \%)$, engineering or engineering technology $(8 \%)$, chemistry $(7 \%)$, health profession $(7 \%)$, business or management $(5 \%)$, and accounting $(5 \%)$. 
Class Size. The college courses students described had fairly small classes. Fifty-six percent of students reported that their course had fewer than 35 students, 26\% said it had 35-75 students, and just $17 \%$ said it had more than 75 students. It is likely that some students were reporting for the enrollment in their section of a course that had a larger total enrollment.

Synchronicity of Online Instruction. When asked about characteristics of their courses after they moved to remote delivery, $76 \%$ of students reported that their course included one or more synchronous ("live") components. Additionally, $84 \%$ of students had courses with some sort of asynchronous components (i.e., recorded lectures, videos, or other materials available online). Overall, $67 \%$ of students reported having both synchronous and asynchronous components in their course after COVID.

\section{Course Satisfaction Before and After the Shift to Remote Instruction}

About half of the students in the survey (51\%) said they were very satisfied with the course they were describing before it went fully online. Students' ratings of their satisfaction with their courses after they moved fully online were dramatically lower, with only $19 \%$ of students being very satisfied with their spring 2020 online course experience. Nevertheless, even with this large decrease in the proportion of very satisfied students, the majority of students $(59 \%)$ described themselves as at least somewhat satisfied with their courses after the shift to remote instruction.

Student satisfaction with their course after it went fully online was lower for students describing STEM courses than for students describing non-STEM courses. Twenty-seven percent of students describing non-STEM courses were very satisfied with their course after it went to remote instruction compared to $15 \%$ of students describing STEM courses. This difference in course satisfaction levels for STEM and non-STEM courses predated the shift to remote instruction: Sixty percent of students describing non-STEM courses said they were very satisfied with their course before it went online compared to $47 \%$ of students describing a STEM course.

The survey also asked students to rate their satisfaction with multiple aspects of their course after it went online, as shown in Table 1. When asked about their satisfaction with their instructor's preparation for teaching the course after it moved online, most students did not blame their instructors for what they perceived as a drop in course quality. More than a third of students (37\%) said they were very satisfied, and 39\% said they were somewhat satisfied with their instructor's preparation for teaching the course post-COVID-19. The area in which satisfaction suffered most after COVID was how well students thought they were learning: Only 17\% of respondents said they were very satisfied with how well they were learning post-COVID-19. Even so, fewer than

half of students expressed dissatisfaction with their learning after their course shifted to remote instruction. 
Table 1

Student Satisfaction Ratings for Aspects of Their Course After COVID

\begin{tabular}{lcccc}
\multicolumn{1}{c}{ Course Aspect } & $\begin{array}{c}\text { Very } \\
\text { Satisfied }\end{array}$ & $\begin{array}{c}\text { Somewhat } \\
\text { Satisfied }\end{array}$ & $\begin{array}{c}\text { Somewhat } \\
\text { Dissatisfied }\end{array}$ & $\begin{array}{c}\text { Very } \\
\text { Dissatisfied }\end{array}$ \\
\hline Instructor's Preparation & $37 \%$ & $39 \%$ & $17 \%$ & $7 \%$ \\
Quality of Course Content & $29 \%$ & $42 \%$ & $22 \%$ & $6 \%$ \\
Quality of Instruction & $29 \%$ & $40 \%$ & $21 \%$ & $10 \%$ \\
How Well You Were Learning & $17 \%$ & $40 \%$ & $27 \%$ & $15 \%$ \\
Course Overall & $19 \%$ & $40 \%$ & $27 \%$ & $13 \%$ \\
\hline
\end{tabular}

Students' responses to questions about these four aspects of their course were all significantly correlated with their response to the questions about their satisfaction with the course overall, with the satisfaction rating for "How Well You Were Learning" having the strongest correlation, $r=0.725, p<0.001$. The remaining correlations were: "Instructor's Preparation," $r=$ $0.640, p<0.001$; "Quality of Course Content", $p=0.662, p<0.001$; and "Quality of Instruction", $r=0.556, p<0.001$.

\section{Barriers to Continuing Learning Online}

The majority of students (96\%) accessed their online courses through an internet connection they already had at home. Internet access at their school, or near their home at another place arranged by their school, was used by just 3\% of students. Another $1 \%$ relied on internet access in another public place for their course.

However, not all internet access is sufficient for digital learning activities. Videoconferencing, which was used in many courses, requires high bandwidth, for example. Even households with high-bandwidth internet may experience connectivity problems when multiple people are online at the same time. Internet connectivity issues were serious enough to interfere with students' ability to attend or participate in their course at least occasionally for $45 \%$ of students, with $16 \%$ of students experiencing such problems often or very often.

Almost a quarter of students (24\%) experienced hardware or software problems serious enough to impact their ability to attend or participate in their course at least occasionally. As one might expect, hardware and software problems were more frequent for the $16 \%$ of students who had frequent internet connectivity issues. Combining responses to the two digital access items, we found that more than 1 in 6 students experienced frequent internet connectivity issues and/or hardware and software problems severe enough to interfere with their ability to continue learning in their courses.

Students also reported problems with continuing their courses online beyond those related to digital access. Asked to rate their experiences with a set of problems they may have faced in trying to continue with their courses after COVID-19, students were most apt to describe staying motivated to do well in the course after it went online as a problem: $79 \%$ of students cited this as a problem (42\% said it was a major problem, and another $37 \%$ said it was a minor problem). As shown in Table 2, other problems were less prevalent than motivation issues but still considered at least a minor problem for a substantial portion of students. Finding a quiet place to work on the 
course online was cited by $55 \%$; fitting the course in with family/home responsibilities by $54 \%$; not knowing where to go for help with the course by $54 \%$; feeling too unwell to participate by $45 \%$; and fitting the course in with a work schedule by $31 \%$.

\section{Table 2}

Experience of Challenges While Completing Courses After COVID-19

\begin{tabular}{lccc} 
Challenge & $\begin{array}{c}\text { Major } \\
\text { Problem }\end{array}$ & $\begin{array}{c}\text { Minor } \\
\text { Problem }\end{array}$ & $\begin{array}{c}\text { Not a } \\
\text { Problem }\end{array}$ \\
\hline $\begin{array}{l}\text { Staying motivated to do well in the course } \\
\begin{array}{l}\text { Finding a quiet place where you could do the course } \\
\text { online }\end{array}\end{array}$ & $\begin{array}{l}42 \% \\
\text { Fitting the course in with your home/family }\end{array}$ & $37 \%$ & $20 \%$ \\
$\begin{array}{l}\text { responsibilities } \\
\text { Not knowing where to get help with the course }\end{array}$ & $17 \%$ & $37 \%$ & $44 \%$ \\
$\begin{array}{l}\text { Feeling too unwell, physically or emotionally, to } \\
\text { participate }\end{array}$ & $14 \%$ & $38 \%$ & $45 \%$ \\
$\begin{array}{l}\text { Fitting the course in with your work schedule, if you } \\
\text { work for pay }\end{array}$ & $8 \%$ & $23 \%$ & $54 \%$ \\
\hline
\end{tabular}

As one might expect, students reporting challenges to continuing their course at a distance also gave lower course satisfaction ratings. Having difficulty maintaining motivation to do well in the course, not knowing where to find help with the course, and feeling too unwell physically or emotionally to participate were the specific challenges most closely related to overall course dissatisfaction. The proportion of students very satisfied with their post-COVID course was only $6 \%$ among those who cited motivation as a major problem compared to $44 \%$ among those who said motivation was not a problem for them. The corresponding satisfaction rates were $5 \%$ for those who said they had a major problem finding where to get course help online compared to $31 \%$ among those who didn't see this as a problem and $10 \%$ for those feeling too unwell to participate compared to $25 \%$ among those not having a wellness problem.

For the $40 \%$ of students who did not report experiencing any challenges to completing their course after COVID-19, the level of satisfaction with the course was $81 \%$ (32\% very satisfied and $49 \%$ somewhat satisfied). For students who experienced four or more challenges (about $10 \%$ of the total sample), the corresponding satisfaction level was just $29 \%$ (10\% as very satisfied and $19 \%$ somewhat satisfied).

\section{Experiences of Students from Low-Income and Minoritized Race/Ethnicity Groups}

The challenges associated with the unplanned transition to remote instruction during COVID-19 were not uniformly distributed across college students. We disaggregated the survey data on digital access issues and other problems for specific student groups: students identifying as female, Hispanic students, Black non-Hispanic students, students from lower-income households (families earning less than $\$ 50,000$ annually), students who were responsible for providing childcare following the transition to remote instruction, working students (more than 20 hours a week outside the home for pay), and non-traditionally aged students (over 26 years of age). We recognize that students' identities are far more complex than the single socially-constructed 
categories explored here, and the exploratory analyses described below were guided by Gutiérrez's (2002) notion of strategic essentialism, which suggests that subtle patterns of inequities can be discerned from large data sets using these categories to elucidate possible differences in an endeavor to advance equity.

Group comparisons found that Hispanic students reported a greater number of challenges to their continued course participation after instruction went online. Fitting the course in with home/ family responsibilities, for example, was a major problem for $27 \%$ of Hispanic students, compared to just $12 \%$ of non-Hispanic White students, $X^{2}(2, \mathrm{n}=755)=24.54, p<.001$. Similarly, $27 \%$ of Hispanic students said finding a quiet place to work on the course was a major problem for them, compared to $16 \%$ of non-Hispanic Whites, $X^{2}(2, \mathrm{n}=755)=11.94, p<.01$. Feeling too unwell, physically or emotionally, to participate in the course was another challenge more prevalent among Hispanic students: $21 \%$ reported this as a major problem, compared to $12 \%$ of non-Hispanic Whites, $X^{2}(2, \mathrm{n}=755)=13.32, p<.01$. More Hispanic students $(24 \%)$ than nonHispanic White students (14\%) also reported having a major problem knowing where to get help with the course after it went online, $X^{2}(2, \mathrm{n}=755)=16.24, p<.001$. The pervasiveness of challenges for Black students was generally in between that for Hispanic students and that for nonHispanic White students, with percentages experiencing a challenge as a major problem that did not differ statistically from those for either of the other two student groups.

Staying motivated to do well in the course, which was the most prevalent challenge overall, was similarly challenging for Hispanic students (46\%) and non-Hispanic White students $(43 \%), p$ $=0.317$, with Black students reporting a significantly lower frequency of this as a major challenge compared to either of the other race/ethnicity groups $(32 \%), X^{2}(2, \mathrm{n}=370)=10.16, p<.001$ and $X^{2}(2, \mathrm{n}=662)=17.51, p<0.001$, respectively.

In terms of technology access, Hispanic students were more likely to experience internet connectivity problems often or very often (23\%) compared to non-Hispanic White students $(12 \%)$, $X^{2}(4, \mathrm{n}=755)=18.13, p<.01$, with the frequency for Black students falling in between $(17 \%)$. Students from lower-income households (annual incomes under $\$ 50,000$ ) were also more likely to experience internet connectivity problems often or very often $(21 \%)$ compared to students from high-income households earning $\$ 100,000$ or more $(12 \%), X^{2}(4, \mathrm{n}=711)=21.27, p<.001$.

Hardware or software issues showed a similar pattern of differences among race/ ethnicity groups. Frequency of hardware and software problems was lower for non-Hispanic White students (5\% experiencing them often or very often) than for underrepresented minority students $(10 \%$ for Hispanic students and $15 \%$ for Black students), $X^{2}(8, \mathrm{n}=1008)=21.74, p<.01$. Hardware and software issues varied also by household income. Just $5 \%$ of students from higher-income households reported having these problems often or very often, compared to $12 \%$ of students from lower-income households, $X^{2}(4, \mathrm{n}=711)=14.95, p<.05$.

To obtain a more holistic view of the level of challenges different kinds of students were contending with, analysts created a nine-point scale for the sum of the number of problems listed in Table 2 a student reported as "major," plus one point for frequent internet connectivity problems and another one for frequent hardware/software problems. Those students experiencing 4 or more challenges can be considered those whose course learning was most negatively impacted by COVID-19. As shown in Table 3 below, the proportion of women reporting four or more major challenges was more than twice that of the proportion of men (15\% versus $7 \%)$. Part of the explanation for the gender difference may relate to childcare responsibilities: Women were more 
likely to be responsible for taking care of a child during the COVID pandemic (of those who had to care for a child, 71\% were female). Hispanic and Black students were more likely to report having experienced four or more challenges ( $21 \%$ and $12 \%$, respectively) than were non-Hispanic white students (7\%). Students in the lowest of the three annual household income groups (annual income of less than $\$ 50,000$ ) were more likely to report having had four or more major challenges ( $18 \%$ versus $8 \%$ of those in the highest- income group).

Table 3

Number of Challenges Faced in Learning Online by Student Characteristics

\begin{tabular}{|c|c|c|c|c|}
\hline \multirow[t]{2}{*}{ Student Characteristic } & \multicolumn{3}{|c|}{ Number of Major Challenges } & \multirow[t]{2}{*}{ Significance Test } \\
\hline & $\begin{array}{c}\text { 0-1 } \\
\text { Challenge }\end{array}$ & $\begin{array}{c}2-3 \\
\text { Challenges }\end{array}$ & $\begin{array}{l}4 \text { or more } \\
\text { Challenges }\end{array}$ & \\
\hline Gender & & & & $X^{2}(2)=26.62 * * *$ \\
\hline Male & $71 \%$ & $22 \%$ & $7 \%$ & \\
\hline Female & $58 \%$ & $27 \%$ & $15 \%$ & \\
\hline Race/Ethnicity & & & & $X^{2}(4)=31.04 * * *$ \\
\hline White, non-Hispanic & $69 \%$ & $24 \%$ & $7 \%$ & \\
\hline Hispanic & $54 \%$ & $26 \%$ & $21 \%$ & \\
\hline Black, non-Hispanic & $62 \%$ & $27 \%$ & $12 \%$ & \\
\hline Household Income & & & & $X^{2}(4)=26.03 * * *$ \\
\hline Lower-income & $54 \%$ & $28 \%$ & $18 \%$ & \\
\hline Mid-income & $66 \%$ & $24 \%$ & $10 \%$ & \\
\hline Upper-income & $70 \%$ & $22 \%$ & $8 \%$ & \\
\hline Childcare Status & & & & $X^{2}(2)=8.21^{*}$ \\
\hline Responsible for childcare & $53 \%$ & $30 \%$ & $17 \%$ & \\
\hline $\begin{array}{l}\text { Not responsible for } \\
\text { childcare }\end{array}$ & $65 \%$ & $24 \%$ & $11 \%$ & \\
\hline Employment & & & & $X^{2}(4)=5.48$ \\
\hline $\begin{array}{l}\text { Working } 21+\text { hours a } \\
\text { week }\end{array}$ & $62 \%$ & $20 \%$ & $18 \%$ & \\
\hline $\begin{array}{l}\text { Working 1-20 hours a } \\
\text { week }\end{array}$ & $61 \%$ & $26 \%$ & $13 \%$ & \\
\hline Not working for pay & $65 \%$ & $24 \%$ & $11 \%$ & \\
\hline Age Category & & & & $X^{2}(2)=0.24$ \\
\hline $\begin{array}{l}\text { Traditionally aged (18- } \\
25)\end{array}$ & $64 \%$ & $25 \%$ & $11 \%$ & \\
\hline Non-traditional age $(26+)$ & $66 \%$ & $23 \%$ & $11 \%$ & \\
\hline
\end{tabular}

\section{Experience of Recommended Instructional Practices}

While many of the challenges that students faced in continuing their learning remotely involved factors college faculty cannot control, other survey responses pointed to influences faculty can control. Instructor choices about how to structure and conduct their courses were associated with a student's level of satisfaction. Below, we discuss the type and frequency of instructional practices used by faculty and their influences on students' ratings of the how well they were learning in their courses after the shift to remote delivery in spring 2020. 
The survey asked students whether their course after COVID included each of eight instructional practices that are prominent in the higher education practitioner literature (American College and University Educators, n.d.; Darby, 2019; Jaggars \& Xu, 2009; Luskin, 2019; Salcido $\&$ Cole, 2018) as contributors to more effective teaching and learning online and also amenable to expression in concrete terms on a survey:

- Assignments that ask students to express what they have learned and what they still need to learn

- Breaking up class activities into shorter pieces than in an in-person course

- Frequent quizzes or other assessments

- Live sessions in which students can ask questions and participate in discussions

- Meeting in breakout groups during a live class

- Personal messages to individual students about how they are doing in the course or to make sure they can access course materials

- Using real-world examples to illustrate course content

- Work on group projects separately from the course meetings

Students' comments in response to an open-ended question about their greatest challenge learning online suggested that they too view these instructional practices as important.

Staying engaged/focused during lecture. Especially in a 1.5 hour class, motivation started to decline rapidly around halfway through. (Student at a private four-year institution)

The videos my professors recorded of themselves giving the lecture was nice because it was actually coming from them instead of a random person on YouTube. (Student at a public four- year institution)

Not as engaging as in class instruction. The courses were too focused on teaching the book and not the real life examples. Being able to ask questions during the lessons was also absent as it was pre-recorded. (Student at a public four-year institution)

When my genetics course was moved online I no longer had access to campus tutoring, and my professor did not hold office hours for students to ask questions and clarify course content. I was left to try and understand all of the material on my own, which was difficult. (Student at a two-year college)

Nearly complete loss of motivation. Especially in classes that only had recorded lectures. It was worlds more manageable in classes where professors checked in periodically and where we had synchronous learning. (Student at a public four-year institution)

Student responses to the eight survey items asking about inclusion of these practices in their course were tabulated. The count of these online instructional practices incorporated in the course after COVID-19 predicted how satisfied students were with their learning in the course, $F$ $(1,1000)=110.1, p<0.001, R^{2}=0.10$. Every additional instructional practice an instructor used increased students' satisfaction with learning by 0.16 (where very dissatisfied $=1.0$, somewhat dissatisfied $=2.0$, somewhat satisfied $=3.0$, and very satisfied $=4.0), p<0.001$. The relationship between count of practices experienced and reported satisfaction with learning is illustrated in Figure 1 below. 


\section{Figure 1.}

Heat Map of the Relationship Between Number of Instructional Practices Reported by Students and Satisfaction with Learning.

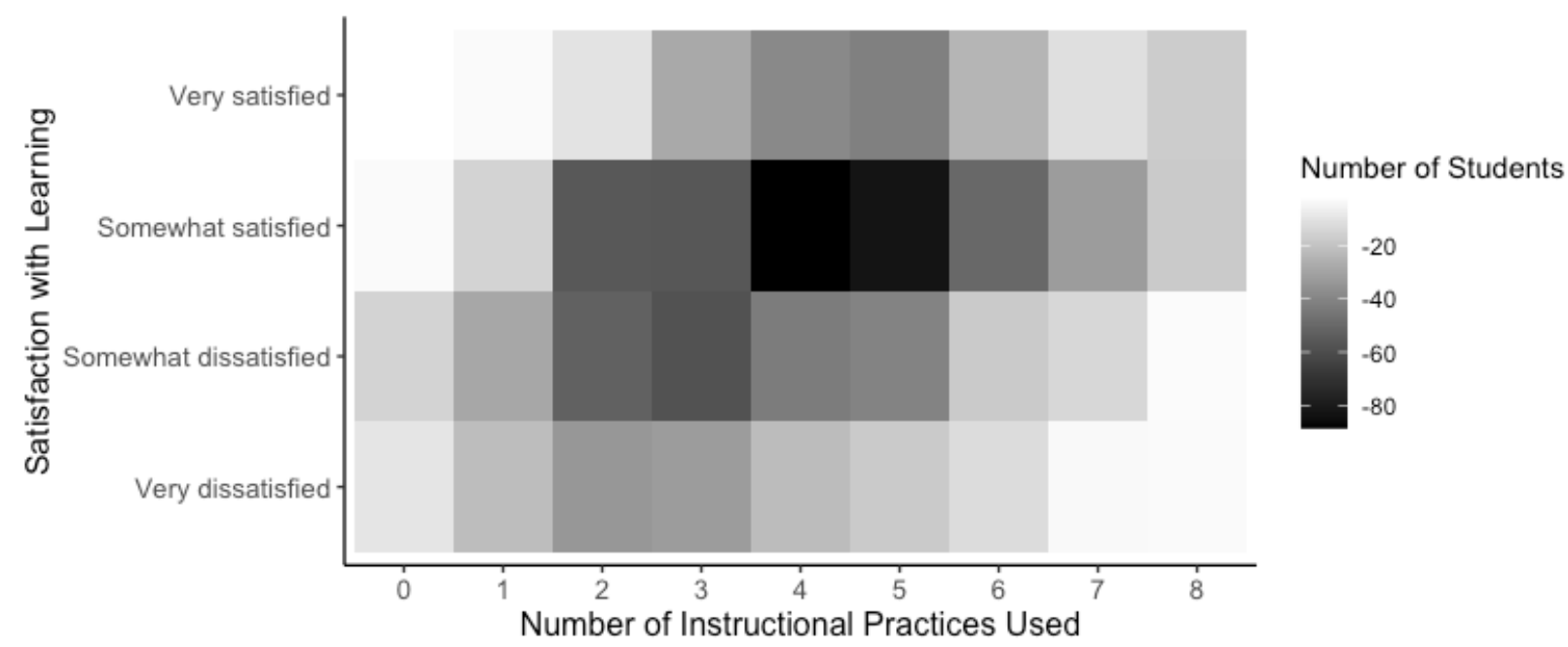

To further parse the role of each of the individual instructional practices on student outcomes, we ran a regression analysis with all eight instructional practices entered into the model simultaneously and calculated standardized regression coefficients for each practice. While the use of standardized regression coefficients complicates interpretability of the results (since they no longer represent units of satisfaction), it has the benefit of allowing researchers to determine the comparative magnitude of the influence of each instructional practice.

The model incorporating presence of each instructional practice (as reported by the student) as predictors of satisfaction with learning found a significant effect, $F(8,961)=22.75, p<0.001$, $R^{2}=0.15$.

When controlling for other practices, four instructional practices significantly predicted students' satisfaction with their learning. These four, in order of magnitude of impact on the outcome largest to smallest, are as follows:

- Personal messages to students about how they are doing in the course $(\beta=0.22, p<0.001)$

- Using examples from the real world to illustrate course content $(\beta=0.18, p<0.001)$

- Assignments having students express what they have learned and still need to learn ( $\beta=$ $0.12, p<0.001)$

- Live sessions in which students could ask questions and participate in discussions $(\beta=$ $0.11, p<0.001)$

These results suggest that while the additive nature of multiple instructional practices is associated with increased satisfaction with learning, not all instructional practices are equally influential. For example, personal messages to students about how they were doing in the course had twice as strong an effect on student's satisfaction as instructors hosting live sessions in which students could ask questions did. 


\section{Experiences of Students from Minoritized Groups}

The challenges associated with the unplanned transition to remote instruction during COVID-19 were not uniformly distributed across college students, as described above. These differential circumstances raise the possibility that the instructional practices associated with student satisfaction might be different for students learning in different contexts. Accordingly, we next disaggregated data of minoritized groups to explore whether individual student characteristics or circumstances correlated with them moderate the relationship between an instructional practice and course satisfaction.

To complete this analysis, linear regressions for specific student groups facing more challenges during COVID were examined individually to ascertain which instructional practices significantly influenced students' satisfaction with their learning when their course was taught remotely. These groups comprise female students, Hispanic students, Black non-Hispanic students, students from lower-income households (families earning less than $\$ 50,000$ annually), students who were responsible for providing childcare following the transition to remote instruction, students who worked $21+$ hours a week, and non-traditionally aged students (26 years of age and older). As above, standardized regression coefficients were calculated to understand the comparative influence of each instructional practice.

For all of the above groups, count of instructional practices significantly predicted student's satisfaction with learning, and the increase in learning satisfaction with each additional instructional practice varied only modestly by student group. Results for key groups are shown in Table 4 below.

\section{Table 4}

Relationship Between Number of Instructional Practices Reported by Students and Satisfaction with Learning for Key Student Groups

\begin{tabular}{lccccc}
\multicolumn{1}{c}{ Student Characteristic } & $\boldsymbol{F}$ & $\boldsymbol{p}$ & $\mathbf{d f}$ & $\boldsymbol{R}^{2}$ & $\begin{array}{c}\text { Increase in } \\
\text { Satisfaction } \\
\text { with +1 IP }\end{array}$ \\
\hline Female & 74.03 & $<0.001$ & 643 & 0.10 & 0.17 \\
Hispanic & 13.83 & $<0.001$ & 227 & 0.05 & 0.12 \\
Black, non-Hispanic & 27.49 & $<0.001$ & 96 & 0.22 & 0.20 \\
Lower-income households $^{\mathrm{a}}$ & 33.75 & $<0.001$ & 366 & 0.08 & 0.14 \\
Responsible for childcare & 6.577 & $<0.05$ & 114 & 0.05 & 0.11 \\
Working 21+ hours a week & 7.839 & $<0.01$ & 226 & 0.03 & 0.09 \\
Non-traditionally aged ${ }^{\mathrm{b}}$ & 20.54 & $<0.001$ & 219 & 0.08 & 0.15 \\
All students & 110.1 & $<0.001$ & 1006 & 0.10 & 0.17 \\
\hline
\end{tabular}

${ }^{a}$ Family Income $<\$ 50,000$ annual; ${ }^{b}$ Students $>25$ years old; IP $=$ Instructional Practice 
However, the particular instructional practices that significantly predicted students' satisfaction with learning varied among the different student groups. Similar to results for the entire sample, personal messages to individual students about how they were doing in the course or to make sure they could access course materials was a significant positive predictor for six of the seven student groups (all except Hispanic students) and was also the strongest relative predictor for six of the seven groups. Using real-world examples to illustrate course content was a significantly positive predictor for five of the seven groups (all but Black, non-Hispanic students and lower-income students). Use of assignments having students express what they have learned and what they still needed to learn was a significantly positive predictor for female students, Hispanic students, Black non-Hispanic students, and lower-income students. Finally, breaking up class activities into shorter pieces than in an in-person course was a significant positive predictor for lower-income students. Standardized regression coefficients for significant predictors by student group can be seen in Table 5. Use of frequent quizzes and using breakout groups in live classes are not included in Table 5 because these two practices, taken individually, did not predict satisfaction with learning significantly for any of the student groups.

\section{Table 5}

Standardized Regression Coefficients for Instructional Practices that are Significant Predictors of Student Satisfaction with their Learning, by Key Student Groups

\begin{tabular}{|c|c|c|c|c|c|c|}
\hline $\begin{array}{l}\text { Student } \\
\text { Characteristic }\end{array}$ & $\begin{array}{l}\text { Personal } \\
\text { messages }\end{array}$ & $\begin{array}{c}\text { Using real- } \\
\text { world } \\
\text { examples }\end{array}$ & $\begin{array}{c}\text { Reflections } \\
\text { regarding } \\
\text { learning }\end{array}$ & $\begin{array}{c}\text { Breaking } \\
\text { up class } \\
\text { activities }\end{array}$ & $\begin{array}{c}\text { Group } \\
\text { projects }\end{array}$ & $\begin{array}{c}\text { Live } \\
\text { discussion } \\
\text { sessions }\end{array}$ \\
\hline Female & $0.23 * * *$ & $0.23 * * *$ & $0.10 *$ & & & \\
\hline Hispanic & & $0.27 * * *$ & $0.14^{*}$ & & & \\
\hline Black, non-Hispanic & $0.35 * *$ & & $0.26 *$ & & & \\
\hline $\begin{array}{l}\text { Lower-income } \\
\text { households }^{\text {a }}\end{array}$ & $0.25 * * *$ & & $0.15^{* *}$ & $0.11^{*}$ & & $-0.14 * *$ \\
\hline $\begin{array}{l}\text { Responsible for } \\
\text { childcare }\end{array}$ & $0.27 * *$ & $0.22 *$ & & & $-0.22 *$ & \\
\hline $\begin{array}{l}\text { Working } 21+\text { hours } \\
\text { a week }\end{array}$ & $0.17 *$ & $0.18 * *$ & & & & \\
\hline $\begin{array}{l}\text { Non-traditionally } \\
\text { aged students }{ }^{b}\end{array}$ & $0.30 * * *$ & $0.21 * *$ & & & $-0.15^{*}$ & \\
\hline All students & $0.22 * * *$ & $0.18 * * *$ & $0.12 * * *$ & & & $0.11 * * *$ \\
\hline
\end{tabular}


Inspection of Table 5 shows that not all the relationships between recommended instructional practices and satisfaction with their learning were positive for all student groups. When controlling for other practices, live sessions where students can ask questions and participate in discussion negatively impacted satisfaction with learning for lower-income students. More indepth exploration of this apparent adverse impact for lower-income students is needed. Lowerincome students were more likely to report experiencing hardware or internet connectivity issues that interfered with their learning, as noted above. Logically, connectivity issues would be expected to impede a student's ability to meaningfully participate in real-time discussions. However, a second regression analysis controlling for internet connectivity and home/family responsibilities did not eliminate the inverse relationship between live discussion sessions and satisfaction with their learning for low-income students. Group projects outside of class time were negative predictors of satisfaction with their learning for students providing childcare and for nontraditionally aged students. This may be due to additional time constraints and family responsibilities that may have made it harder for learners from these two student groups to participate in group projects after COVID.

\section{Discussion}

Despite the sharply lower student satisfaction with their courses after they shifted to remote instruction in response to the COVID-19 pandemic (from 51\% to $19 \%$ of students "very satisfied"), there are positive messages in our survey data. The use of a varied set of online teaching practices recommended in the literature resulted in higher student satisfaction with the course post-COVID19. In courses incorporating at least six of the eight recommended online teaching practices, $35 \%$ of students were very satisfied and $40 \%$ somewhat satisfied after COVID-19. Courses incorporating fewer of the recommended practices had lower satisfaction ratings, as described above.

Of the eight recommended online teaching practices covered in the survey, the two with the most impact on student satisfaction were the inclusion of personal messages to students about how well they were doing in the course (courses including this practice had $28 \%$ of students very satisfied compared to just $8 \%$ very satisfied for those without) and course activities that asked students to reflect on what they had learned and what they still needed to learn $(28 \%$ of students in courses with this feature were very satisfied compared to $11 \%$ in courses without). Moreover, even the most pervasive challenge cited by students - maintaining motivation to do well in the course once it moved online-was significantly less common in courses using the practice of sending students personalized messages about how they were doing ( $56 \%$ of students in courses that did not include personal messages found staying motivated to be a major problem, compared to $43 \%$ of students in courses that used personal messages).

At the same time, analyses for key groups of students revealed that not all instructional practices are significant positive predictors of learning satisfaction for all kinds of students. There were even a few cases in which an instructional practice described on the survey had a negative relationship with satisfaction with their learning for some kinds of students. These results suggest that it is advisable for instructors to provide multiple ways for students to engage in their online courses and demonstrate their learning in order to create remote learning environments that are equitable for all kinds of students. 
The good news in these findings is that instructional practices that predict student satisfaction are things that college instructors can implement in their courses, and in fact, there are many technology tools available to help them do so. Some learning systems automatically generate lists of students who have not logged in for a specified time period or who have fallen significantly behind the expected rate for mastering course objectives. Prompts for students to write about aspects of course material they have reviewed but don't feel they understand are built into a number of courseware products. Some online assessment tools ask students to rate their confidence that their answer was correct after responding to each test item.

Moreover, research suggests that involving teams of faculty, instructional designers, and faculty development staff in redesigning curriculum and instruction can result in a better course and is also a very effective form of professional learning as faculty gain insights and know-how from each other as well as from their instructional design and faculty development colleagues (Wieman, 2017). A number of resources provide guidance on how to establish multifunctional course teams and organize their course improvement work (Cavanaugh et al., 2020; O'Keefe, Rafferty, Gunder, \& Vignare, 2020).

As we look to an uncertain future, it is not clear how much postsecondary instruction will be fully online in coming academic terms. But even when in-person classes can be held without undue health risks, it will be important to remember the lessons of the spring 2020 COVID-19 experience. Having students reflect on their own learning, instructor efforts to relate course material to real-world examples, and personalized communications that convey a concern with helping students learn all increase course satisfaction. These practices are very much in line with the Athabasca Community of Inquiry model and should be explored as predictors of course outcomes. The practices of holding live discussion sessions and group projects are also congruent with the model, however, and were associated with lower satisfaction among lower-income and older students, as well as those providing childcare. The fact that several often-recommended practices may lead to lower course satisfaction for some kinds of students (holding other instructional practices equal) warrants further investigation. In the interim, instructors are encouraged to collect information on the quality of technology access and the competing demands their students are dealing with and to consider this information and provide alternative means of engagement when designing course activities and group projects.

\section{Acknowledgements}

This work was supported by grants to Digital Promise Global from the Bill \& Melinda Gates Foundation (INV-016705) and the National Science Foundation (DUE 2029642). Any opinions, findings, conclusions, or recommendations are those of the authors and do not necessarily reflect the position, policy, or endorsement of their organizations or the funding agency. 


\section{References}

American College and University Educators. (n.d.). ACUE's Online Teaching Toolkit. https://acue.org/online-teaching-toolkit/

Anderson, M., \& Kumar, M. (2019). Digital divide persists even as lower-income Americans make gains in tech adoption. FactTank News in the Numbers. Pew Research. https://www.pewresearch.org/fact-tank/2019/05/07/digital-divide-persists-even-as-lowerincome-americans-make-gains-in-tech-adoption/

Asch, S. (2020). Vermont colleges loosen grading as Covid-19 crisis raises equity concerns. VTDIGGER. Vermont Journalism Trust. https:/vtdigger.org/2020/04/05/vermont-collegesloosen-grading-as-covid-19-crisis-raises-equity-concerns/

Bali, S., \& Liu, M. C. (2018). Students perceptions toward online learning and face-to-face learning courses. Journal of Physics: Conference Series, 1108. https://iopscience.iop.org/article/10.1088/1742-6596/1108/1/012094/meta

Bernard, R. M., Abrami, P. C., Borokhovski, E., Wade, A., Tamim, R., Surkes, M. A., et al. (2009). A meta-analysis of three interaction treatments in distance education. Review of Educational Research, 79(3), 1243-1289. https://doi.org10.3102/0034654309333844v1

Bettinger, E., \& Loeb, S. (2017). Promises and pitfalls of online education. Evidence Speaks Report, 2(15), 1-4.

Blatt, L., Schunn, C. D., Votruba-Drzal, E., \& Rottman, B. M. (2020). International Journal of STEM Education, 7, 58. https://doi.org/10.1186/s40594-020-00253-0

Cavanagh, T., Chen, B., Lahcen, R., \& Paradiso, J. (2020). Constructing a design framework and pedagogical approach for adaptive learning in higher education: A practitioner's perspective. International Review of Research in Open and Distributed Learning, 21(1), 173-197. https://doi.org/10.19173/irrodl.v21i1.4557

Dabbagh, N., Bass, R., Bishop, M., Costelloe, S., Cummings, K., Freeman, B., Frye, M., Picciano, A. G., Porowski, A., Sparrow, J., \& Wilson, S. J. (2019). Using technology to support postsecondary student learning: A practice guide for college and university administrators, advisors, and faculty. Institute of Education Sciences, What Works Clearinghouse, National Center for Education Evaluation and Regional Assistance.

Daempfle, P. A. (2004). An analysis of the high attrition rates among first-year college science, math, and engineering majors. Journal of College Student Retention, 5(1), 37-52. http://dx.doi.org/10.2190/DWQT-TYA4-T20W-RCWH

Darby, F. (2019, April 17). How to be a better online teacher. The Chronicle of Higher Education. https:/www.chronicle.com/article/how-to-be-a-better-online-teacher/\#1

Eddy, S. L., \& Hogan, K. A. (2014). Getting under the hood: How and for whom does increasing course structure work? Life Science Education, 13, 453-468.

Fishman, B., and Dede, C. (2016). Teaching and technology: New tools for new times. In D. H. Gitomer and C.A. Bell (Eds.), Handbook of Research on Teaching (5th ed.). American Educational Research Association. 
Fouad, N. A., Hackett, G., Smith, P. L., Kantamneni, N., Fitzpatrick, M., Haag, S., \& Spencer, D. (2010). Barriers and supports for continuing in mathematics and science: Gender and educational level differences. Journal of Vocational Behavior, 77(3), 361-373. https://doi.org/10.1016/j.jvb.2010.06.004

Freeman, S., Eddy, S. L., McDonough, M., Smith, M. K., Okoroafor, N., Jordt, H., \& Wenderoth, M. P. (2014). Active learning increases student performance in science, engineering, and mathematics. Proceedings of the National Academy of Sciences. http://www.pnas.org/ content/111/23/8410.full

Garrison, D. R. (2009). Online community of inquiry review: Social, cognitive, and teaching presence issues. Journal of Asynchronous Learning Networks, 11(1), 61-72.

Gutiérrez, R. (2002). Enabling the practice of mathematics teachers in context: Toward a new equity research agenda. Mathematical Thinking and Learning, 4(2-3), 145-187.

Jaggars, S. S., \& Xu, D. (2016). How do online course design features influence student performance? Computers \& Education, 95, 270-284.

Horspool, A., \& Yang, S. S. (2010). A comparison of university student perceptions and success learning music online and face-to-face. MERLOT Journal of Online Learning and Teaching, 6, 15-29. http://jolt.merlot.org/vol6no1/horspool_0310.pdf

Lichtenstein, G., Chen, H. L., Smith, K. A., \& Maldonado, T. A. (2014). Retention and persistence of women and minorities along the engineering pathway in the United States. In A. Johri and B. M. Olds (Eds.), Cambridge Handbook of Engineering Education Research. Cambridge University Press.

Luskin, B. J. (2019). 12 best practices in online teaching and learning. Psychology Today, Luskin Learning Psychology Series, N, 44. https://www.psychologytoday.com/us/blog/themedia-psychology- effect/201903/12-best-practices-in-online-teaching-and-learning

Means, B., and Neisler, J., with Langer Research Associates. (2020a). Suddenly online: A national survey of undergraduates during the COVID-19 pandemic. Digital Promise.

Means, B., \& Neisler, J. (2020b). Unmasking inequality: STEM course experiences during the COVID-19 pandemic. Digital Promise Global.

National Academies of Sciences, Engineering, and Medicine. (2019). Minority serving institutions: America's underutilized resource for strengthening the STEM workforce. National Academies Press. https://doi.org/10.17226/25257

O’Keefe, L., Rafferty, J., Gunder, A., \& Vignare, K. (2020, May 18). Delivering high-quality instruction online in response to COVID-19: Faculty playbook. Every Learner Everywhere. http://www.everylearnereverywhere.org/resources

Platt, C. A., Raile, A. N. W., \& Yu, N. (2014). Virtually the same? Student perceptions of the equivalence of online classes to face-to-face classes. MERLOT Journal of Online Learning and Teaching, 10(3), 489-503.

Ramsey, L. R., Betz, D. E., \& Sekaquaptewa, D. (2013). The effects of an academic environment intervention on science identification among women in STEM. Social Psychology of Education, 16(3), 377-397. 
Salcido, A., \& Cole, J. (2018, September 10). Best practices for teaching online. Teach Online. Arizona State University. https://teachonline.asu.edu/2018/09/best-practices-for-teachingonline/

Schwartzman, R. (2007). Refining the question: How can online instruction maximize opportunities for all students? Communication Education, 56, 113-117. httpl://www.doi.org/ $10.1080 / 03634520601009728$

Smith, J., Lewis, K., Hawthorne, L, \& Hodges, S. (2013). When trying hard isn't natural: Women's belonging with and motivation for male-dominated STEM fields as a function of effort expenditure concerns. Personality and Social Psychology Bulletin, 39(2), 131-143.

Strayhorn, T. L. (2012). College students' sense of belonging: A key to educational success for all students. Routledge.

Walton, G. M., \& Cohen, G. L. (2011). A brief social-belonging intervention improves academic and health outcomes of minority students, Science, 331(6023): 1447-1451.

Winkelmes, M-A. (2013). Transparency in teaching: Faculty share data and improve students' learning, Liberal Education, 99(2): 48-55.

Winkelmes, M-A., Bernacki, M., Butler, J., Zochowski, M., Golonics, J., \& Weavil, K. H. (2016). A teaching intervention that increases underserved college students' success. Peer Review, 18(1/2).

$\mathrm{Xu}$, D., \& Jaggars, S. S. (2011). The effectiveness of distance education across Virginia's community colleges: Evidence from introductory college-level Math and English courses. Educational Evaluation and Policy Analysis, 33(3), 360-377

Xu, D., \& Jaggars, S. S. (2013). The impact of online learning on students' course outcomes: Evidence from a large community and technical college system. Columbia University, Teachers College, Community College Research Center. 